\title{
VACCINOLOGÍA
}

\section{Influenza: Profilaxis mediante la inmunización activa}

\author{
ALBERTO FICA C. ${ }^{1}$
}

\section{INFLUENZA: PROPHYLAXIS THROUGH ACTIVE IMMUNIZATION}

The available medical alternatives for confronting influenza virus infection have been optimized by the development of more secure and well tolerated vaccines than the original immunization alternatives. The efficacy of active immunization against influenza has been demostrated in various clinical trials that support its benefit in immunized people with rates of efficacy over $70 \%$ in general population and at least $50 \%$ in patients over 65 years of age. The parenteral formulas constitute now the principal alternative in the market (as whole virus, split vaccine or purified antigens) and can be administered universally, including immunosuppressed patients, because it contains inactivated virus. The attenuated virus vaccines are under development, they are not available yet and they could be contraindicated in some immunosuppresed patients. Its advantage lies in the administration by nasal route that would facilitate its adherence during immunization campaigns.

Key words: Influenza, Immunoprophylaxis, Vaccines

\section{INTRODUCCION}

La influenza es una enfermedad respiratoria aguda viral altamente contagiosa, de morbilidad elevada y capaz de provocar complicaciones potencialmente letales en pacientes de riesgo. El manejo de esta enfermedad es tanto preventivo como terapéutico y el adecuado conocimiento de estas opciones es de gran importancia para la promoción de salud, para disminuir sus complicaciones y costos asociados y para controlar su letalidad.

En este artículo se revisarán algunos conceptos básicos del virus influenza y las estrategias de control basadas en la inmunización activa. También se revisará la aplicación de la vacuna en poblaciones específicas -incluyendo la población laboralmente activa- sus reacciones adversas y el uso de vacunas atenuadas.

\section{CONCEPTOS BASICOS}

El virus influenza se transmite por aerosoles en gotas diseminadas por la tos o el estornudo. La transmisión por contacto directo también contribuye a la diseminación de esta enfermedad, especialmente en la población infantil. Existen tres tipos de virus influenza denominados $\mathrm{A}$, $\mathrm{B}$ y $\mathrm{C}$, los dos primeros tienen 8 segmentos de ARN y el tipo $C$ tiene 7 segmentos, una envoltura o manto lipídico y moléculas de superficie

\footnotetext{
${ }^{1}$ Unidad de Infectología. Departamento de Medicina, Hospital Clínico Universidad de Chile.
} 
denominadas hemaglutinina $(\mathrm{H})$ y neuraminidasa $(\mathrm{N})$, estructuras proteicas que representan antígenos fundamentales en la epidemiología y en la prevención de la influenza. De los tres tipos mencionados sólo los tipos A y B tienen importancia epidemiológica. El virus influenza A se clasifica en subtipos de acuerdo a las diferencias genéticas y serológicas asociadas con las dos glicoproteínas de superficie. Al menos 15 subtipos de hemaglutinina y 9 de neuraminidasa han sido descritos ${ }^{1}$, aunque sólo algunas combinaciones de ellos han afectado al hombre. Tanto el subtipo H1N1 como el H3N2 del virus influenza A circulan en el mundo desde fines de los años $70^{1}$.

La hemaglutinina viral participa en la adsorción a la célula y en el inicio de la infección. Los anticuerpos producidos contra esta proteína tienen propiedades neutralizantes sobre el virus. La neuraminidasa actúa desdoblando glicoproteínas presentes en células del huésped, lo que permite la salida y diseminación del virus luego de la replicación viral. Los anticuerpos contra esta estructura impiden la diseminación viral, pero no la infección inicial. El virus influenza presenta variaciones genéticas frecuentes en los segmentos de ARN. Estas modificaciones son el resultado de fenómenos de recombinación, reordenamientos, inserciones, mutaciones puntuales o deficiencias en la capacidad editora de las enzimas que participan en la replicación o transcripción viral. Ellas originan cambios en la secuencia nucleotídica de la neuraminidasa y/o de la hemaglutina, modificando su composición aminoacídica e identidad antigénica. La magnitud de este cambio puede ser menor, explicada por mutaciones puntuales en los segmentos de ARN, un fenómeno conocido como "variación antigénica" (antigenic drift) o por un cambio mayor en la secuencia aminoacídica de estas glicoproteínas "cambio antigénico" (antigenic shift). En el primer caso, los cambios discretos en la secuencia aminoacídica de las glicoproteínas, generan variantes dentro de un subtipo de hemaglutinina o neuraminidasa. Este tipo de variación ocurre tanto en el virus influenza $A$ como en el B y se denomina utilizando datos sobre el sitio y año del aislamiento viral respectivo (por ejemplo A/Chile/83 o B/Panamá/90). En el segundo caso, la variación genética y aminoacídica es explicada por un evento de reordenamiento genético que introduce una hemaglutinina o neuraminidasa inmunológicamente diferente a la(s) circulante(s) en años recientes. Este fenómeno ocurre infrecuentemente, sólo en el virus influenza A, y aparece ligado a la transferencia hacia el hombre de nuevos subtipos desde una fuente animal como el cerdo, los que son generados por reordenamientos genéticos entre segmentos de ARN. La coinfección con virus influenza A de diferentes subtipos humanos y avícolas en este animal, posibilita este reordenamiento genético ${ }^{1}$.

Las variaciones aminoacídicas y antigénicas en la hemaglutinina o neuraminidasa disminuyen la capacidad de neutralización de los anticuerpos presentes en los pacientes, reestableciendo la susceptibilidad a la infección. Cuando el cambio es menor y asociado a la aparición de variantes dentro de un subtipo, sólo una fracción de la población humana se puede infectar y la letalidad aparece restringida a pacientes debilitados. En contraste, cuando aparecen nuevos subtipos, la mayor parte de la población se enferma luego del contagio, la letalidad por esta enfermedad aumenta y puede incluir pacientes previamente sanos. Solamente el virus influenza A presenta cambios de esta naturaleza, lo que explica su capacidad para generar pandemias e incrementar la letalidad de esta infección (Tabla 1).

Las variaciones y cambios antigénicos en el virus influenza obligan a renovar anualmente la formulación de la vacuna de tal manera que en ella estén representadas las cepas y subtipos que han prevalecido o aparecido en la temporada anterior. La composición de estas vacunas es habitualmente trivalente, conteniendo cepas o antígenos que otorgan una cobertura razonable contra diferentes antígenos $\mathrm{H}$ y $\mathrm{N}$ del virus A y también del virus B. En el caso de que se detectara la aparición de un nuevo subtipo, que potencialmente puede producir una pandemia, la vacuna se formula con una sola cepa.

La existencia de una enfermedad provocada por un virus que continuamente modifica su composición antigénica haciendo la experiencia inmune previa menos eficiente, que por otra parte, se asocia a complicaciones potencialmente graves en diversos grupos de pacientes 
y, para la cual existen pocas alternativas terapéuticas con un efecto significativo sobre la severidad de la enfermedad, determina que la intervención más importante en su control sea la prevención de ella, dirigida especialmente a los grupos de mayor riesgo.

\section{Diagnóstico de influenza}

El diagnóstico clínico de influenza está basado en la presencia de un cuadro febril agudo asociado a al menos dos de los siguientes síntomas: mialgias, cefalea, tos u odinofagia. La sensibilidad de este conjunto sintomático es alta durante la temporada epidémica y alcanza al $100 \%$. Su especificidad es de $58 \%$ según cálculos realizados por el autor con información disponible de publicaciones que utilizaron estos criterios para reclutar pacientes y que confirmaron adecuadamente los casos de influenza ${ }^{2}$. El diagnóstico de certeza de esta infección puede obtenerse por aislamiento viral, por detección de antígenos virales en una muestra respiratoria mediante técnicas de inmunofluorescencia o inmunoensayo enzimático, o por un alza en los títulos de anticuerpos específicos entre dos muestras pareadas separadas por al menos 4 semanas $^{2}$. La detección de antígenos virales desde una muestra respiratoria puede ser realizada en pocas horas o minutos según la técnica utilizada, facilitando el diagnóstico de esta infección. La IFD permite alcanzar el diag- nóstico en menos de 4 horas y las técnicas de enzima inmunoensayo o de ensayo colorimétrico, en menos de 1 hora ${ }^{1}$. La detección mediante IFD tiene una sensibilidad aproximada de $67 \%$ y una especificidad superior a $90 \%$ (comunicación personal de L. Fidel Avendaño, Programa de Virología, Facultad de Medicina, Universidad de Chile). Las técnicas enzimáticas tienen sensibilidades y especificidades similare ${ }^{1} \mathrm{y}$, en general, permiten la detección de los dos tipos de virus influenza. Algunas de estas técnicas están disponibles en Chile. El aislamiento viral puede ser utilizado en el diagnóstico clínico, aunque la latencia involucrada en la obtención de los resultados limita su valor diagnóstico y terapéutico. Sin embargo, esta metodología tiene una gran importancia epidemiológica para monitorizar el inicio y evolución de la epidemia anual y la aparición de nuevos subtipos. Varios centros centinelas participan en Chile con este objetivo.

\section{VACUNA ANTIGRIPAL}

La vacuna de la influenza se prepara anualmente antes de la temporada de ataque de este virus para cada hemisferio. Los estudios centinelas permiten proponer la composición antigénica de estas vacunas que habitualmente es trivalente, es decir contiene componentes antigénicos de tres cepas prevalentes que per-

Tabla 1. Diferencias de importancia epidemiológica entre virus influenza tipo A y B

\begin{tabular}{lcc}
\hline \multicolumn{1}{c}{ Característica } & Virus A & Virus B \\
\hline $\begin{array}{l}\text { Variación genética en H o N } \\
\text { (antigenic drift) }\end{array}$ & Presente & Presente \\
$\begin{array}{l}\text { Cambio genético en H o N } \\
\text { (antigenic shift) }\end{array}$ & Presente \\
$\begin{array}{l}\text { Capacidad de provocar pandemias } \\
\begin{array}{l}\text { Importancia en la composición } \\
\text { de la vacuna anual }\end{array}\end{array}$ & $\begin{array}{l}\text { Los subtipos y variantes relevantes } \\
\text { de influenza A deben estar presen- } \\
\text { tes en la vacuna (2 subtipos desde } \\
\text { hace varias décadas). }\end{array}$ & Sólo un subtipo viral en la vacuna. \\
& & Ausente \\
\hline
\end{tabular}

$\mathrm{H}$ : hemaglutinina; $\mathrm{N}$ : neuraminidasa. 
miten cubrir razonablemente a la población humana contra subtipos específicos del virus A y B. La vacuna debe aplicarse al comienzo del período otoñal para permitir una seroconversión antes del inicio de la temporada.

En Chile, al igual que para otros países templados, el período epidémico se inicia habitualmente durante el otoño y con una duración aproximada de 10 semanas. La epidemia se inicia en forma variable entre fines del mes de abril y mediados de mayo de cada año ${ }^{3}$.

Los grupos vulnerables o de riesgo están definidos por su propensión a presentar complicaciones graves o riesgo de muerte. Los pacientes mayores de 65 años y aquellos que portan alguna enfermedad pulmonar o cardíaca crónica, asma, inmunosupresión u otra condición, tienen mayor susceptibilidad para desarrollar complicaciones graves y deben ser considerados en los programas de inmunización (Tabla 2). Las complicaciones observadas en estos pacientes explican el gran impacto en la salud pública que tiene esta infección. Por ejemplo, las tasas de mortalidad por influenza en Chile durante el período 1990-1999 fueron al menos 10 veces superiores en el grupo de $65 \mathrm{y}$ más años que las observadas en los pacientes entre 55 y 64 años y 100 veces superiores a las de pacientes de 45 a 54 años $^{3}$. Durante los años con mayor tasa de incidencia, esta mortalidad se incrementa en cada grupo etario en forma paralela al aumento de los casos de influenza ${ }^{3}$. Los pacientes en terapia salicílica crónica tienen mayor riesgo de desarrollar el síndrome de Reye luego de la infección aguda y también deben ser incluidos en los programas preventivos. La vacuna también se recomienda para personas sanas que tengan un contacto habitual con pacientes vulnerables, tales como los trabajadores del sector salud. La aplicación en mujeres embarazadas se comenta más adelante.

\section{Presentaciones de la vacuna}

Las vacunas utilizadas en las campañas de inmunización contra la influenza están preparadas con virus inactivados ya sea como viriones completos, virus fragmentados (split vaccine) $o$ antígenos de superficie purificados. Estas vacunas son aplicadas por vía intramuscular y presentan una tasa de reacciones adversas similar entre ellas, excepto en el caso de la presentación con virus fragmentados que está asociada a una menor tasa de efectos adversos en la población infantil.

Recientemente se han desarrollado vacunas con virus atenuados, adaptados al frío, de aplicación intranasal, que no pueden replicarse más allá de la temperatura permisiva en la fosa nasal, impidiendo por lo tanto su diseminación al resto del árbol respiratorio, pero posibilitando una estimulación antigénica local y sistémica. Estas vacunas están actualmente siendo evaluadas y aún no se dispone de formulaciones comerciales.

\section{La eficacia de vacunas para influenza con virus inactivados}

A pesar de que algunos estudios no han logrado demostrar un efecto protector de la vacuna, el análisis combinado (meta-análisis) de los resultados obtenidos con estudios desarrollados en cohortes de pacientes y que han involucrado a pacientes mayores, ha permitido demostrar una eficacia protectora superior a $50 \%$ con la vacuna en este grupo específico para prevenir la influenza ${ }^{4}$. El beneficio de la inmunización activa contra la influenza incluye también un impacto en la reducción de los casos de neumonía $(\sim 50 \%)$, hospitalizaciones por neumonía, influenza o por cualquier condición respiratoria en pacientes seniles con factores de riesgo $(\sim 50 \%)^{4,5}$. La aplicación de la vacuna también ha estado asociada a una reducción en el riesgo de muerte en estos pacientes $(\sim 70 \%)$ y ha demostrado ser también una estrategia costo-efectiva ${ }^{4,5}$. Estudios de tipo caso-control también han logrado demostrar un impacto significativo en estos mismos parámetros ${ }^{4}$. La eficacia de la vacuna para prevenir casos confirmados de influenza en pacientes mayores fue confirmada en un estudio randomizado contra placebo, de tipo doble cie$\mathrm{go}^{6}$. La eficacia protectora disminuye si la epidemia anual de influenza está asociada a la aparición de variantes dentro de un subtipo viral no incluidos en la vacuna (antigenic drift), excepto si existe cruce antigénico entre la cepa circulante y los componentes de la vacuna, en 
Tabla 2. Indicaciones de inmunización activa contra influenza

\author{
Personas sobre 65 años de edad \\ Personas bajo 65 años de edad con algunas de las siguientes condiciones: \\ Diabetes mellitus \\ Cardiopatía \\ Patología pulmonar crónica \\ Asma \\ VIH seropositivos y SIDA \\ Tratamiento inmunosupresor \\ Internados en casas de reposo o de ancianos \\ Pacientes pediátricos o adolescentes en terapia salicílica crónica \\ Mujeres con un embarazo de segundo o tercer trimestre durante la epidemia \\ Personal de salud incluyendo el de asilos de ancianos, casas de reposo, hogares de pacientes terminales, etc.
}

cuyo caso sí podría esperarse una misma eficacia. La vacunación no ha sido efectiva en aquellos casos en que la vacuna no ha incluido nuevos subtipos virales de reciente aparición epidemiológica (antigenic shift ${ }^{4}$.

Además de los beneficios en la morbilidad, la vacuna contra la influenza puede tener un impacto en disminuir la mortalidad de pacientes institucionalizados cuando el personal de salud es inmunizado. El uso de tal estrategia, permitió disminuir en forma significativa las tasas de mortalidad de los pacientes institucionalizados en centros que vacunaron a su personal en forma comparativa a aquellos centros que no lo hicieron (17 versus $10 \%)^{7}$.

\section{Evaluación de vacunas atenuadas}

Las vacunas inactivas han sido comparadas con formulaciones de virus atenuados aplicadas en aerosol nasal. En un estudio en personas sanas se observó una reducción de 74 y $76 \%$ en la frecuencia de casos comprobados por cultivo viral de influenza A por los subtipos H1N1 y H3N2 respectivamente, al utilizar vacuna con virus inactivados. La reducción observada con la vacuna atenuada fue de $85 \%$ para los casos comprobados de infección por virus $\mathrm{H} 1 \mathrm{~N} 1$, pero sólo de $58 \%$ para los eventos asociados al virus de tipo $\mathrm{H} 3 \mathrm{~N} 2^{8}$.

Otros estudios desarrollados en adultos sanos han evaluado la eficacia protectora de formulaciones conteniendo dos subtipos atenuados de virus influenza A y han demostrado una reducción en la morbilidad respiratoria entre los vacunados en comparación con el grupo control, incluyendo un claro efecto para detener la curva epidémica en el mes de mayor incidencia, y además reducir el ausentismo laboral $^{9}$. El grupo que recibió placebo presentó un aumento estacional de casos 3 veces superior al observado en el grupo vacunado.

También se han desarrollado ensayos combinando los efectos de la vacuna inactivada con la aplicación de una vacuna atenuada intranasal en pacientes ancianos institucionalizados logrando demostrar una mayor eficacia con la aplicación conjunta que con la aplicación aislada de vacuna inactivada, tanto en la reducción de casos de influenza A documentados por laboratorio (60\% de eficacia) como en aquellos casos con un cuadro clínico sugerente (56\% de eficacia protectora) ${ }^{10}$.

La eficacia de las vacunas atenuadas ha sido analizada mayoritariamente en personas sanas y no se dispone de mayor información sobre su utilidad en pacientes de alto riesgo. El único estudio desarrollado en pacientes mayores incluyó paralelamente una inmunización parenteral con virus inactivos. Por otra parte la condición atenuada de los virus contenidos en la vacuna hará necesaria una rigurosa evaluación de la eficacia y de las posibles reacciones adversas en pacientes mayores o infectados con VIH, antes de su comercialización. Estudios recientes han informado que el uso de vacunas atenuadas en pacientes infectados con VIH ( $\sin$ SIDA) no se ha asociado a una mayor 
frecuencia de complicaciones en comparación con un grupo control y tampoco a aumentos en la carga viral o disminución en el recuento de linfocitos $\mathrm{CD} 4^{11}$.

\section{Reacciones adversas}

El uso masivo de la vacuna de la influenza ha sido resistido por la creencia de que se trata de una vacuna mal tolerada con importantes reacciones adversas locales o sistémicas. Un estudio reciente evaluó este aspecto demostrando que las reacciones adversas al aplicar una vacuna inactivada por vía parenteral en pacientes mayores de 65 años, no eran más frecuentes que las observadas con la administración de placebo $^{12}$.

El desarrollo y uso de vacunas con componentes antigénicos purificados ha permitido minimizar la reacciones adversas. La frecuencia de reacciones adversas en niños es mayor al administrar vacuna con viriones completos, en comparación con la administración de virus fragmentado. La menor tasa de reacciones adversas en niños que reciben virus fragmentado ha favorecido su uso de esta formulación en esta población, aunque la respuesta serológica ha sido inferior contra ciertas variantes virales en comparación a la obtenida con viriones comple$\operatorname{tos}^{13}$. Ello ha obligado a utilizar dosis de refuerzo en pacientes pediátricos que no han tenido una exposición previa con la vacuna.

\section{Uso de la vacuna en pacientes con condi- ciones especiales}

La aplicación de la vacuna en algunos pacientes portadores de patologías crónicas tales como esclerosis múltiple, artritis reumatoidea, cáncer o infección por VIH, ha sido resistida por el temor al desarrollo de complicaciones asociadas a la patología de base de estos pacientes. Un escenario similar ocurre con aquelos pacientes en tratamiento anticoagulante. En los últimos años varios de estos aspectos se han evaluado, permitiendo tener más claridad sobre la seguridad de la vacuna en este tipo de pacientes. En esta sección también se incluye un análisis sobre el uso de la vacuna en mujeres embarazadas.
En pacientes infectados con virus de inmunodeficiencia humana. La aplicación de la vacuna en pacientes infectados con VIH ha sido resistida debido a la respuesta inmune parcial que tienen estos pacientes ante la exposición a diferentes antígenos y por la posibilidad de incrementar la replicación del virus VIH y su carga viral. Su aplicación fue evaluada recientemente, demostrándose en un estudio que la vacuna de influenza fue altamente eficaz $(100 \%)$ en disminuir casos confirmados de influenza ${ }^{14} \sin$ provocar un aumento de la carga viral o a una disminución de los niveles de linfocitos CD4. Estos resultados despejan las dudas sobre la vacunación en pacientes infectados con VIH. El mismo grupo que reportó la inocuidad de la vacuna influenza había señalado previamente un aumento de la carga viral de VIH y a una disminución en los niveles de linfocitos CD4 en una serie menor de $\operatorname{casos}^{15}$. Otros estudios han confirmado que la vacuna no tiene un impacto en aumentar la carga viral o en acelerar la declinación de los niveles de linfocitos CD4 circulantes en pacientes afectados por el VIH, en comparación con aquellos vacunados con placebo ${ }^{16}$. La eficacia de vacunas atenuadas en pacientes afectados por el VIH no ha sido reportada aún.

Esclerosis múltiple. La aplicación de la vacuna antigripal en pacientes con esclerosis múltiple no se ha acompañado de una exacerbación de la enfermedad neurológica hasta 6 meses después de su aplicación, por lo que su aplicación en este escenario se considera segura ${ }^{17}$.

Artritis reumatoidea. El uso de esta vacuna es necesario en estos pacientes debido al mayor riesgo de enfermedades respiratorias letales para esta condición ${ }^{18}$ y en niños con artritis reumatoidea en terapia crónica con salicílicos, para evitar el desarrollo del síndrome de Reye luego de la infección viral. La producción de anticuerpos en ellos es similar a controles sanos.

Cáncer. Este aspecto ha sido explorado en una pequeña serie de pacientes con leucemia o tumores sólidos que recibieron vacuna con virus inactivados, y en los que se estudió la presencia y magnitud de la respuesta serológica en comparación con controles sanos. Los resultados indican que un porcentaje menor de pacientes con cáncer logran una respuesta serológica 
(71 versus $94 \%$ en controles) y que su magnitud también es más baja. La respuesta no se correlacionó al sexo o edad del paciente, recuento de linfocitos, tipo de tumor, estadío de la enfermedad o tipo de quimioterapia utilizada. El factor más importante parece ser el momento de la vacunación puesto que la tasa de respuesta fue ostensiblemente menor cuando la aplicación fue realizada en el momento de la quimioterapia en lugar de efectuarla entre las quimioterapias. La recomendación es no evitar la vacunación en estos pacientes y aplicarla antes o después de un curso de quimioterapia. Sólo vacunas con virus inactivados pueden ser utilizadas en estos pacientes ${ }^{19}$.

Tratamiento anticoagulante. Los pacientes que reciben tratamiento anticoagulante pueden recibir la correspondiente dosis de vacuna parenteral, ya sea por vía subcutánea o intramuscular, con el mismo grado de respuesta inmune (la vacuna no está contraindicada en estos pacientes). En un estudio la frecuencia de problemas derivados de su terapia anti coagulante fue baja y similar al usar ambas alternativas ${ }^{20}$. Alternativamente los pacientes pueden utilizar una forma de aplicación nasal con virus inactivado o cumplir un programa de quimioprofilaxis con amantadina, oseltamivir o zanamivir durante el período epidémico (ver artículo al respecto en pág 126).

Mujeres embarazadas. La vacuna en estas pacientes ha sido recomendada por el riesgo de muerte asociado a esta infección observado durante algunas pandemias de influenza hasta fines de los años 50. A pesar de que esta letalidad no ha sido documentada nuevamente, publicaciones recientes dan cuenta de un mayor riesgo de hospitalizaciones por diferentes condiciones cardiovasculares durante la temporada de influenza en mujeres embarazadas. Este riesgo aparece en el segundo trimestre y se incrementa hacia el final del embarazo ${ }^{21}$.

Ausentismo laboral e inmunización. Impacto de la vacuna anti influenza en población sana economicamente activa y en el personal de salud

La vacuna anti influenza reduce efectivamente el número de episodios febriles de causa respiratoria en trabajadores adultos sanos, independiente a su severidad, como así mismo los días sintomáticos totales, y es capaz de reducir el número de días de licencias médicas ${ }^{22}$. Estos datos fueron obtenidos en un estudio doble ciego randomizado usando una vacuna atenuada trivalente por vía nasal contra placebo.

Los efectos adversos observados en trabajadores sanos al utilizar una vacuna con virus inactivados por vía parenteral, no resultaron ser diferentes en comparación con el uso de placebo $^{23}$. La frecuencia de fiebre, mialgias, fatiga y cefalea fue similar en ambos grupos. Estos datos desmitifican la percepción de que en trabajadores sanos la aplicación de la vacuna anti gripal podría ser acompañada de una mayor frecuencia de efectos adversos con una consiguiente repercusión laboral que anularía su efecto beneficioso.

Esta vacuna también ha logrado una alta reducción de casos confirmados de influenza $\mathrm{A}$ $(88 \%)$ o B $(89 \%)$ en adultos vacunados por vía parenteral ${ }^{24}$. En un estudio desarrollado específicamente con personal de salud pediátrico, la vacuna con virus influenza inactivo fue capaz de reducir en un $28 \%$ los días de ausentismo laboral ${ }^{25}$.

Estudios complementarios del tipo caso-control también han demostrado una reducción en la frecuencia de casos de influenza, en los días de ausentismo laboral y en el ahorro en días perdidos de trabajo, incluso al considerar el costo del programa de vacunación ${ }^{26}$.

El problema actual no está relacionado a la tolerabilidad de la vacuna sino en asegurar una cobertura poblacional a los grupos de riesgo que deben ser alcanzados y que implica sensibilizar al equipo de salud para lograr este objeti$\mathrm{vo}^{27}$.

\section{RESUMEN}

Las alternativas médicas disponibles para enfrentar las infecciones por el virus influenza se han optimizado por el desarrollo de vacunas más seguras y mejor toleradas que las alternativas de inmunización originales. La eficacia de la inmunización activa para este virus ha sido demostrada en varios ensayos clínicos que han 
indicado un claro beneficio para la población vacunada y que alcanza eficacias superiores a $70 \%$ en la población general y al menos $50 \%$ en los pacientes sobre 65 años de edad. Las formulaciones parenterales constituyen actualmente la alternativa predominante en el mercado (ya sea con virus totales, fragmentados o con antígenos purificados) y pueden ser aplicadas universalmente, incluso en pacientes inmunosuprimidos, porque contienen virus inactivados. Las alternativas con virus atenuados están en desarrollo, no están aún disponibles y podrían estar contraindicadas en algunos pacientes inmunosuprimidos. Su ventaja radica en su aplicación nasal que podría facilitar su adherencia en las campañas de inmunización.

\section{BIBLIOGRAFIA}

1.- COX N J, SUBBARAO K. Influenza. Lancet 1999; 354: 1277-82.

2.- MONTO A S, FLEMING D M, HENRY D, DE GROOT R, MAKELA M, KLEIN T et al. Efficacy and safety of the neuraminidase inhibitor zanamivir in the treatment of influenza A and B virus infections. J Infect Dis 1999; 180: 254-61.

3.- SOTOMAYOR V, AGUILERA X. Situación de la influenza en Chile: 1999. El vigía. Boletín de Vigilancia Epidemiológica de Chile 1999; 2: 2-3.

4.- GROSS P A, HERMOGENES A W, SACS H S et al. The efficacy of influenza vaccine in elderly persons: A meta-analysis an review of the literature. Ann Intern Med NEW 1995; 123: 518.

5.- NICHOL K L, GOODMAN M. The health and economic benefits of influenza vaccination for healthy and at-risk persons aged 65 to 74 years. Pharmacoeconomics 1999; 16 (Suppl 1): 63-71.

6.- GOVAERT $\mathrm{T} \mathrm{M}$, THIJS $\mathrm{C} \mathrm{T}$, MASUREL $\mathrm{N}$, SPRENGER M J, DINANT G J, KNOTTNERUS J A. The efficacy of influenza vaccination in elderly individuals. A randomized double-blind placebocontrolled trial. JAMA 1994; 272: 1661-5.

7.- POTTER J, STOTT D J, ROBERTS M A, ELDER A G, O'DONNELL B, KNIGHT P V et al. Influenza vaccination of health care workers in long-term-care hospitals reduces the mortality of elderly patients. J Infect Dis 1997; 175: 1-6.

8.- EDWARDS K M, DUPONT W D, WESTRICHT M K, PLUMMER W D Jr, PALMER P S, WRIGHT $\mathrm{P}$ F. A randomized controlled trial of cold-adapted and inactivated vaccines for the prevention of influenza A disease. J Infect Dis 1994; 169: 68-76.

9.- ROCCHI G, CARLIZZA L, ANDREONI M, RAGONA G, PIGA C, PELOSIO A et al . Protection from natural infection after live influenza virus immunization in an open population. J Hyg (Lond) 1979; 82: 231-6.

10.- TREANOR J J, MATTISON H R, DUMYATI G, YINNON A, ERB S, O'BRIEN D et al. Protective efficacy of combined live intranasal and inactivated influenza A virus vaccines in the elderly. Ann Intern Med 1992; 117: 625-33.

11.- KING J C, TREANOR J, FAST PE, WOLFF M, YAN L, IACUZIO D et al. Comparison of the safety, vaccine virus shedding, and immunogenicity of influenza virus vaccine, trivalent, types $\mathrm{A}$ and $\mathrm{B}$, live cold-adapted, administered to human immunodeficiency virus (HIV)-infected and non-HIV infected adults. J Infect Dis 2000; 181: 725-8.

12.- MARGOLIS K L, NICHOL K L, POLAND G A, PLUHAR R E. Frequency of adverse reactions to influenza vaccine in the elderly. A randomized, placebo-controlled trial. JAMA 1990; 264: 1139-41.

13.- GROSS P A, ENNIS FA, GAERLAN P F, DENSON L J, DENNING C R, SCHIFFMAN D. A controlled double-blind comparison of reactogenicity, immunogenicity, and protective efficacy of wholevirus and split-product influenza vaccines in children. J Infect Dis 1977; 136: 623-32.

14.- TASKER S A, TREANOR J J POAXTON W B, WALLACE M R. Efficacy of influenza vaccination in HIV-infected persons. A randomized, double-blind, placebo-controlled trial. Ann Intern Med 1999; 131: 430-3.

15.- TASKER $S$ A, O'BRIEN W A, TREANOR J J, WEISS P J, OLSON P E, KAPLAN A $\mathrm{H}$ et al. Effects of influenza vaccination in HIV-infected adults: a double-bind, placebo-controlled trial. Vaccine 1998; 16: 1039-42.

16.- GLESBY M J, HOOVER D R, FARZADEGAN H, MARGOLICK J B, SAAH A J. The effect of influenza vaccination on human immunodeficiency virus type 1 load: a randomized, double-blind, placebocontrolled study. J Infect Dis 1996; 174: 1332-6.

17.- MILLER A E, MORGANTE L A, BUCHWALD L Y, NUTILE S M, COYLE P K, KRUPP L B et al. A multicenter, randomized, double-blind, placebocontrolled trial of influenza immunization in multiple sclerosis. Neurology 1997; 48: 312-4.

18.- CHALMERS A, SCHEIFELE D, PATTERSON C, WILLIAMS D, WEBER D, SHUCKETT R et al. Immunization of patients with rheumatoid arthritis against influenza: a study of vaccine safety and immunogenicity. J Rheumatol 1994; 21: 1203-6.

19.- ORTBALS D W, LEIBHABER H, PRESANT C A, VAN AMBURG A L 3D, LEE J Y. Influenza immunization of adult patients with malignant diseases. Ann Intern Med 1977; 87: 552-7.

20.- DELAFUENTE J C, DAVIS J A, MEULEMAN J $\mathrm{R}$, JONES R A. Influenza vaccination and warfarin anticoagulation: a comparison of subcutaneous and intramuscular routes of administration in elderly men. Pharmacotherapy 1998; 18: 631-6.

21.- NEUZIL K M, REED G W, MITCHEL E F, SIMONSEN L, GRIFFIN M R. Impact of influenza 
on acute cardiopulmonary hospitalizations in pregnant women. Am J Epidemiol 1998; 148: 1094-102.

22.- NICHOL K L, MENDELMAN P M, MALLON K P, JACKSON L A, GORSE G J, BELSHE R B et al. Effectiveness of live, attenuated intranasal influenza virus vaccine in healthy, working adults: a randomized controlled trial. JAMA 1999; 282: 137-44.

23.- NICHOLS K L, MARGOLIS K L, LIND A, MURDOCH $\mathrm{M}$ et al. Side effects associated with influenza vaccination in healthy working adults. A randomized, placebo, controled trial. Arch Intern Med 1996; 156: 1546-50.

24.- WILDE J A, MCMILLAN J A, SERWINT J, BUTTA J, O'RIORDAN M A, STEINHOFF M C. Effectiveness of influenza vaccine in health care professionals: a randomized trial. JAMA 1999; 281: 908-13.

25.- SAXEN H, VIRTANEN M. Randomized, placebocontrolled double blind study on the efficacy of influenza immunization on absenteeism of health care workers. Pediatr Infect Dis J 1999; 18: 779-83.

26.- CAMPBELL D S, RUMLEY M H. Costeffectiveness of the influenza vaccine in a healthy, working-age population. J Occup Environ Med 1997; 39: 408-14.

27.- FICA A, ANTUNEZ M, CUEVAS K, RODRIGUEZ A, ARAVENA P. Prescripción de la vacuna antiinfluenza por médicos institucionales y estudiantes de especialidades médicas en un hospital docente. Rev Chil Infect 2001; 18 (1): 20-7.

Correspondencia a:

Alberto Fica Cubillos.

E-mail: afica@machi.med.uchile.cl 